\title{
Endoscopic ultrasound-guided fine-needle tissue acquisition from a subepithelial lesion in the distal ileum using the forward-viewing echoendoscope
}

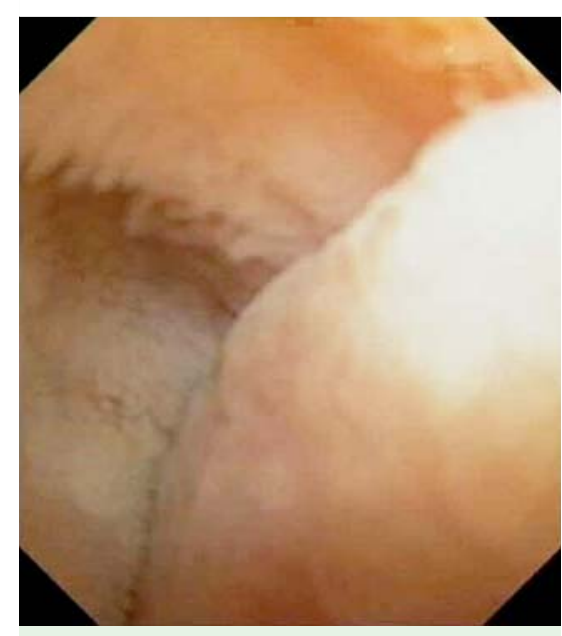

Fig. 1 Endoscopic image of the subepithelial lesion in the terminal ileum in a 68-year-old woman.

In a context of rapidly expanding indications for endoscopic ultrasound (EUS)guided procedures, a dedicated forwardviewing linear therapeutic echoendoscope (FV-EUS) has been developed and tested for different clinical indications [1-3]. The frontal endoscopic view combined with the exit of the working channel at the tip of the echoendoscope offers some unique advantages over the standard cur- vilinear echoendoscope. This has opened up new possibilities for EUS-guided fineneedle aspiration and tissue acquisition (EUS-FNTA) from difficult targets and combined endoscopic/EUS treatment [3, 4].

We have previously described the possibility of using FV-EUS to navigate easily through the colon to reach and sample extracolonic lesions located above the sigmoid tract [4]. We now report the first case of intubation of the ileocecal valve followed by sampling of a distal ileal lesion performed using the FV-EUS.

A 68-year-old woman with a 13-year history of ulcerative colitis was found on routine surveillance colonoscopy to have a $1.5 \mathrm{~cm}$ lesion in the terminal ileum that presented characteristics suggestive of a subepithelial lesion with a normal-appearing overlying mucosal layer ( $\bullet$ Fig. 1 ). To exclude extrinsic compression, comput-

\section{Video 1}

Intubation of the ileocecal valve under endoscopic guidance, endoscopic ultrasonographyguided fine-needle tissue acquisition from the detected subepithelial lesion, and histologic features of the collected specimen. ed tomography was carried out and confirmed the presence of a wall thickening or lesion at the level of the terminal ileum, close to the ileocecal valve.

Colonoscopy using the FV-EUS was attempted and was completed up to the cecum. The terminal ileum was then intubated and, under EUS guidance, a hypoechoic lesion measuring $14 \times 10 \mathrm{~mm}$ and confined to the third wall layer was detected.EUS-FNTA using a 19-gauge needle was performed ( $\bullet$ Fig. 2, Video 1) and a tissue sample obtained ( Fig.3), which revealed a serotonin-secreting neuroendocrine tumor with a Ki67 proliferation index of less than $1 \%$, corresponding to a grade 1 tumor (NET G1). The patient underwent right hemicolectomy, and definitive assessment of the surgical specimen confirmed the diagnosis of a grade 1 serotonin-secreting neuroendocrine tumor with lymph node involvement (pT3N1) [5].

\section{Endoscopy_UCTN_Code_TTT_1AS_2AF}

Competing interests: None

\section{Domenico Galasso ${ }^{1}$, Fabia Attili ${ }^{1}$, Franco Scaldaferri ${ }^{2}$, Giuseppe Vanella ${ }^{1}$, Frediano Inzani ${ }^{3}$, Guido Costamagna ${ }^{1}$, Alberto Larghi ${ }^{1}$}

${ }^{1}$ Digestive Endoscopy Unit, Catholic University, Rome, Italy

${ }^{2}$ Gastroenterology Division, Catholic University, Rome, Italy

${ }^{3}$ Department of Pathology, Catholic University, Rome, Italy
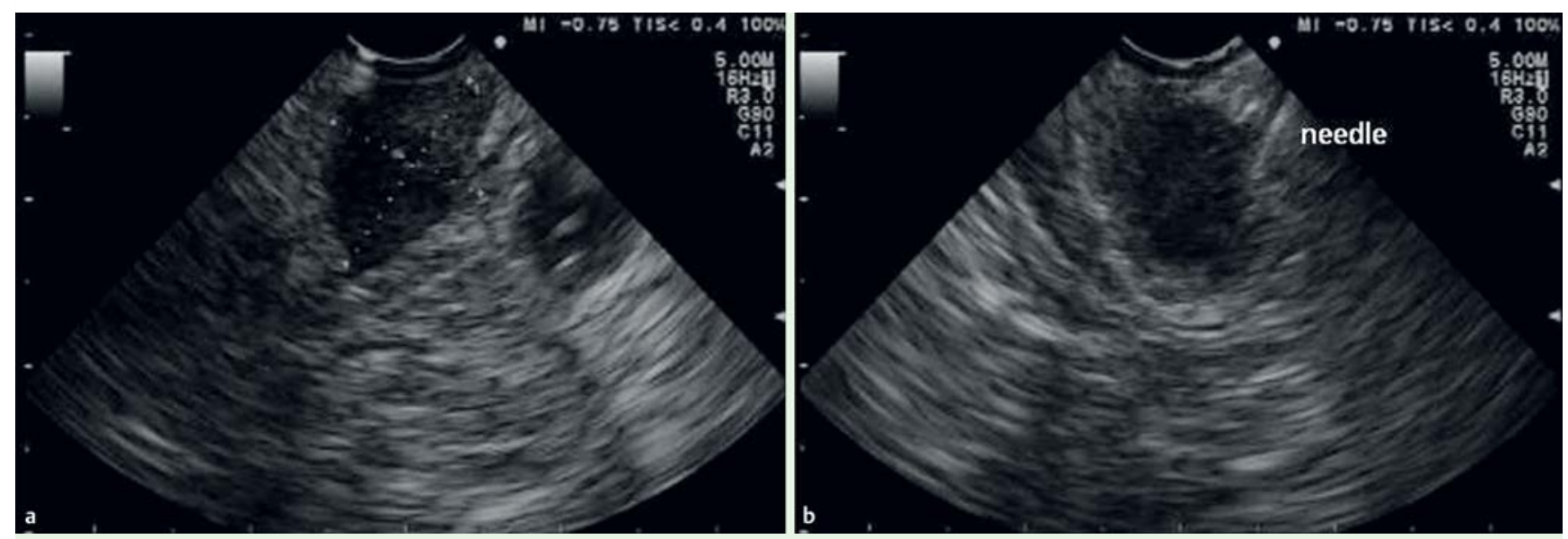

Fig. 2 a Endoscopic ultrasound (EUS) view of the subepithelial lesion in the terminal ileum, demonstrating a hypoechoic lesion measuring $14 \times 10 \mathrm{~mm}$ and confined to the submucosal layer. b EUS-guided fine-needle tissue acquisition from the lesion using a 19-gauge needle. 


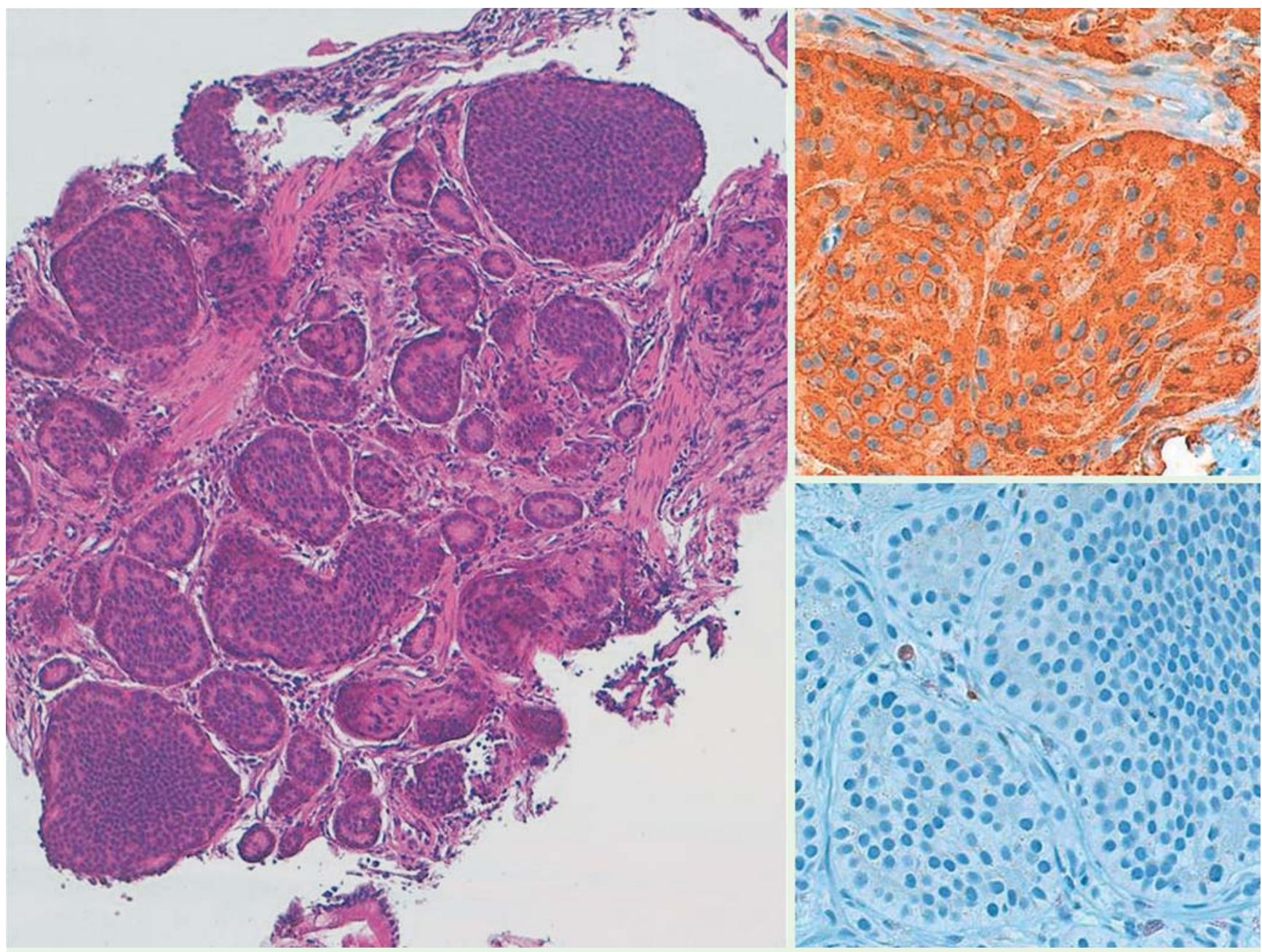

Fig. 3 Tissue specimen showing solid nests of neoplastic polygonal cells with mild atypia (main image), immunoreactivity to chromogranin A (right upper), and a Ki-67 proliferation index of about $1 \%$ (right lower). Staining: hematoxylin and eosin (H\&E) (main image), immunoperoxidase (smaller images).

\section{References}

1 Fusaroli P, Ceroni L, Caletti G. Forward-view endoscopic ultrasound: a systematic review of diagnostic and therapeutic applications. Endosc Ultrasound 2013; 2: 64-70

2 Larghi A, Lecca PG, Ardito F et al. Evaluation of hilar biliary strictures by using a newly developed forward-viewing therapeutic echoendoscope: preliminary results of an ongoing experience. Gastrointest Endosc 2009; 69: 356-360

3 Larghi A, Seerden TC, Galasso D et al. EUSguided therapeutic interventions for un- common benign pancreaticobiliary disorders by using a newly developed forwardviewing echoendoscope (with videos). Gastrointest Endosc 2010; 72: 213-215

4 Uchida N, Galasso D, Seerden TC et al. EUSFNA of extracolonic lesions by using the forward-viewing linear echoendoscope. Gastrointest Endosc 2010; 72: 1321 - 1323

5 Bosman FT, Carneiro F, Hruban RH et al., eds. WHO classification of tumours of the digestive system. Lyon: IARC Press; 2010

\section{Bibliography}

DOI http://dx.doi.org/

10.1055/s-0034-1364947

Endoscopy 2014; 46: E214-E215

(c) Georg Thieme Verlag KG

Stuttgart · New York

ISSN 0013-726X

\section{Corresponding author \\ Alberto Larghi, MD, PhD}

Università Cattolica del Sacro Cuore Largo A. Gemelli 8

00168 Rome

Italy

Fax: +39-06-30156581

albertolarghi@yahoo.it 